\title{
LA PUESTA EN DUDA DEL CONCEPTO DE VALIDEZ EN EL RECONOCIMIENTO DE LAUDOS ANULADOS
}

[Questioning the Concept of Validity in the Recognition of Annulled Awards]

\author{
Horacio Andaluz Vegacenteno* \\ Universidad Privada de Santa Cruz de la Sierra, Bolivia
}

\begin{abstract}
RESUMEN
El reconocimiento en 2013 en los Estados Unidos de un laudo mexicano anulado por los tribunales mexicanos parece traer consigo la afirmación implícita de que es legalmente posible reconocer un laudo anulado. Esa afirmación, en sí misma, es un reto al concepto jurídico de validez, desde que significa que lo que ha sido declarado nulo puede, al mismo tiempo, ser válido para producir efectos jurídicos. El punto de este artículo es develar la naturaleza jurídica detrás del reconocimiento de laudos anulados. Para hacer eso, el artículo revisa nueve decisio-
\end{abstract}

\begin{abstract}
The recognition of the United States of an award annulled by the Mexican courts in 2013 seems to entail the implicit statement that it is legally feasible to recognise an annulled award. This statement, in itself, is a challenge to the legal concept of validity, since it means that what was declared null can, at the same time, be valid to produce legal effects. This article is aimed at unveiling the legal nature behind the recognition of the annulled awards. In order to achieve the foregoing, the article revises nine legal decisions, from 1984 to 2013, and concludes that there are three
\end{abstract}

RECIBIDO el 23 de octubre y ACEPTADo el 15 de diciembre de 2014

* Profesor de la Universidad Privada de Santa Cruz de la Sierra, Bolivia, Master en Derecho Internacional (Universidad Complutense de Madrid), antiguo alumno de la Academia de La Haya de Derecho Internacional, Master of Laws-Derecho Constitucional y Filosofía del Derecho (Harvard Law School). Domicilio postal: Casilla 4710, Santa Cruz de la Sierra, Bolivia. Correo electrónico: handaluz@post.harvard.edu 
nes judiciales, de 1984 a 2013, y concluye que detrás del reconocimiento de laudos anulados hay tres hipótesis diferentes, cada una de ellas con una naturaleza distintiva y ninguna de ellas es un reto al concepto de validez jurídica.

Palabras Clave

Convención de sobre reconocimiento y ejecución de sentencias arbitrales extranjeras - Jurisdicción primaria - Jurisdicción secundaria - Laudos anulados. different hypotheses, each of them different in nature and none of them challenges the concept of legal validity behind the recognition of annulled awards.

KEYWORDS

Convention for the Recognition and Enforcement of Foreign Arbitral Awards - Primary jurisdiction - Secondary jurisdiction - Annulled awards.

\section{INTRODUCCIÓN}

Este trabajo constituye un ejercicio interpretativo de una práctica judicial. Que se reconozcan laudos anulados parece retar al concepto jurídico de validez. En efecto, solo puede ser materia de reconocimiento lo que es jurídicamente válido. Lo inválido es jurídicamente inexistente. Y a lo que el derecho le niega existencia, no puede el mismo derecho reconocerle validez a sus efectos. Hasta aquí bien. Pero lo cierto es que la jurisprudencia conoce supuestos de reconocimiento de laudos anulados. Entonces, una de dos: $i)$ o la jurisprudencia ha reformulado el concepto jurídico de validez, haciendo que se pueda reconocer como válido lo inválido; o ii), simplemente, el reconocimiento de laudos anulados no es tal, bien porque no es en naturaleza un acto de reconocimiento, o bien, porque los laudos no fueron, en naturaleza también, anulados. Queda claro de su solo planteamiento que la primera hipótesis está excluida y que el reconocimiento de laudos anulados tiene una explicación mucho más simple y referenciada en el derecho positivo. Esa explicación viene de develar su naturaleza jurídica. Y para esto debe diferenciarse el reconocimiento de laudos anulados en una jurisdicción secundaria (parte II) del reconocimiento de laudos anulados por sus jurisdicciones primarias (parte III); y acá debe distinguirse el fundamento de la aplicación del derecho más preferente (parte III,) del fundamento del orden público violado por la decisión de anulación (parte III,2).

Para dotar a este ejercicio de consistencia interna, se ha tomado jurisprudencia que viene desde 1984 (asunto "Pabalk") hasta 2013 (asunto "COMMISA"). La diferenciación referida en el párrafo anterior es ya un ejercicio interpretativo de la práctica judicial, que ha develado la naturaleza común de los asuntos "Nicor" y "Karaha Bodas" (parte II) y su distingo de naturaleza con los asuntos "Pabalk", "Hilmarton", "Chromalloy", "Baker Marine" y 
"Spier" (parte III.1), encontrando en el segundo fundamento vertido en estos tres últimos, a su vez, una entidad hermanada con los asuntos "TermoRío" y "COMMISA" (parte III.2).

$Y$ ya que es una interpretación de una práctica judicial, he querido que dicha práctica se muestre en sus propios textos, por justicia con ella. Todas las traducciones son libres. La numeración de los párrafos responde a la unidad conceptual de cada uno de ellos.

\section{RECONOCIMIENTO DE LAUDOS ANULADOS POR UNA JURISDICCIÓN SECUNDARIA}

1. Cuando laudos anulados por una jurisdicción secundaria son reconocidos por otras jurisdicciones secundarias, el acto de reconocimiento del laudo anulado es inocuo para el concepto jurídico de validez. La razón: la anulación de un laudo en una jurisdicción secundaria tiene que tomarse, en naturaleza jurídica, tan solo como una denegatoria de su reconocimiento, porque ninguna jurisdicción secundaria está autorizada por la Convención de sobre reconocimiento y ejecución de sentencias arbitrales extranjeras ("“"Convención de Nueva York"” de 1958) para declarar la invalidez de un laudo nacional de otra jurisdicción (artículo V,1 e). Por tanto, ninguna jurisdicción secundaria está atada a la actuación ultra vires de su par, lo que le permite reconocer el laudo que la otra ha dicho anular.

2. Por regla, al reconocimiento y la ejecución de laudos extranjeros les son aplicables las normas de la citada "Convención de Nueva York". La razón: hay 147 Estados obligados por ella y, desde su entrada en vigor en 1959 (7 de junio) a la fecha, su aplicación ha generado un vasto y generalmente uniforme cuerpo de jurisprudencia comparada, que allana las dudas sobre su interpretación. Por su técnica de regulación, la "Convención de Nueva York" se aplica aún a laudos emitidos en Estados que no son parte en ella. Es consecuencia de que su cumplimiento esté a cargo del Estado del foro, que queda impuesto de obligaciones unilaterales (artículo I,1): lo obligan sin que exista relación sinalagmática con el Estado del lugar del arbitraje. En esto la "Convención de Nueva York" se aleja, para bien, de la técnica de regulación propia del derecho de los tratados, donde cada tratado es fuente de un entramado de obligaciones bilaterales entre los Estados vinculados por él. Y como un Estado se obliga frente a otro en la medida exacta de las obligaciones que éste tiene con aquel, la relación jurídica entre ellos se construye a partir de la identidad de sujetos (Estados) y materias comprometidas (obligaciones). Como la Convención no participa de esta forma de producción de obligaciones expactu, siempre que el Estado en el que se busca reconocer y ejecutar un laudo sea parte en ella, ésta le será aplicable. La excepción: que el Estado 
requerido hubiese formulado reserva de reciprocidad, en cuyo caso aplicará la Convención sólo a los laudos provenientes de otro Estado parte (artículo I,3). Por su lenguaje omnicomprensivo, la Convención se aplica a todos los laudos que necesiten de reconocimiento: su artículo I sólo se refiere a "sentencias arbitrales", sin distinguir entre ellas. Por tanto, la Convención es aplicable a laudos comerciales y a laudos de inversiones, dictados en arbitrajes nacionales o en arbitrajes internacionales. La excepción: que el Estado requerido hubiese formulado reserva de materia comercial, en cuyo caso aplicará la Convención sólo a los laudos que decidan controversias "consideradas comerciales por su derecho interno" (artículo I,3). Y, por su naturaleza procesal, la jurisprudencia comparada no ha tenido inconveniente en aplicar la Convención a laudos emergentes de arbitrajes nacidos de convenios arbitrales celebrados antes de su entrada en vigor, como pasó en el caso "Fotochrome, Inc. v. Copal Company"1 (1975). Acá la Corte de Apelaciones del Segundo Circuito de Estados Unidos aplicó la Convención sosteniendo que ella no afectaba los derechos sustantivos de las partes, sino que simplemente establecía un procedimiento uniforme de reconocimiento y ejecución. Lo propio sostuvo la Cámara de los Lores en Inglaterra, en "State of Kuwait v. Frederick Snow \& Partners"2 (1984), y Chapdelaine narra que la Corte italiana de Casación también ha dado aplicación inmediata a la Convención ${ }^{3}$.

3. El reconocimiento es un asunto de derecho internacional privado. Es un juicio sobre la admisibilidad de los efectos de una decisión extranjera, reconociéndole la misma eficacia que produciría una decisión del foro de naturaleza equiparable. Es un acto formal y declarativo. Formal, porque prescinde de revisar el fondo del asunto. No se valoran los hechos, sino que se resuelve sobre las condiciones formales tasadas para pronunciar el reconocimiento o negarlo. Y declarativo, porque deja que la cosa juzgada extranjera produzca los mismos efectos que produciría en su Estado de origen. El reconocimiento puede denegarse por siete razones, especificadas en el artículo V de la "Convención de Nueva York" ${ }^{4}$. De éstas, las cinco primeras

${ }^{1} 517$ F.2d 512. Fuente: https://bulk.resource.org/courts.gov/c/F2/517/517. F2d.512.74-2082.568.html

2 [1984] A.C. 426. Fuente: http://www2.ambrac.nl/kli-ka-csg/document. aspx?id=ipn 8190

${ }^{3}$ Cf. Chapdelaine, Pascale, The Temporal Application of the New York Arbitration Convention of 1958: Retroactivity or Immediate Application? en Arbitration International, 8 (1992), p. 78.

4 " 1 . Solo se podrá denegar el reconocimiento y la ejecución de la sentencia, a instancia de la parte contra la cual es invocada, si esta parte prueba ante la autoridad competente del país en que se pide el reconocimiento y la ejecución: a) Que las partes en el acuerdo a que se refiere el Artículo 2 estaban sujetas a alguna incapacidad en virtud de la Ley que le es aplicable o que dicho acuerdo no es valido en virtud de la Ley a que las 
operan a pedido y prueba de quien las invoca; las dos restantes lo hacen aún de oficio. Respecto del laudo extranjero, el Estado del foro es una jurisdicción secundaria: es un foro en el que se busca su reconocimiento y ejecución, nada más; no uno cuyo derecho condicione su validez. El condicionamiento de validez de una decisión lo ejerce el sistema jurídico que le otorga su nacionalidad, y sólo a éste corresponde, por lo mismo, el poder para declarar su nulidad. La suya es una jurisdicción primaria, por ser sus tribunales los de la ley del lugar del arbitraje. Por tanto, si en una jurisdicción secundaria se anulase un laudo extranjero, en derecho tal pronunciamiento debiera leerse tan sólo como una denegación del reconocimiento, nada más. Esa sería su naturaleza jurídica. Así develada, el reconocimiento de un laudo anulado en una jurisdicción secundaria sería inocuo para el concepto jurídico de validez. La razón: la decisión de anulación no ostentaría oponibilidad erga omnes, porque solamente lo que no es válido para la jurisdicción primaria es jurídicamente inexistente para las demás jurisdicciones.

4. Tan simple como esto: emitido el laudo, el derecho lo reviste con una presunción de validez. Es una pura consecuencia de su carácter jurídico. Toda la producción del derecho se rige por dicha presunción: las normas son válidas hasta que el órgano atribuido de competencia por el sistema jurídico no declare su invalidez. Si constitutivamente el sistema jurídico requiere de un acto formal para que una norma comience a existir como derecho, también requiere de una declaratoria formal de invalidez para que cese su existencia

partes lo han sometido, o si nada se hubiera indicado a este respecto, en virtud de la Ley del país en que se haya dictado la sentencia; o b) Que la parte contra la cual se invoca la sentencia arbitral no ha sido debidamente notificada de la designación del arbitro o del procedimiento de arbitraje o no ha podido, por cualquier otra razón, hacer valer sus medios de defensa; o c) Que la sentencia se refiere a una diferencia no prevista en el compromiso o no comprendida en las disposiciones de la cláusula compromisario, o contiene decisiones que exceden de los términos del compromiso o de la cláusula compromisoria; no obstante, si las disposiciones de la sentencia que se refieren a las cuestiones sometidas al arbitraje pueden separarse de las que no han sido sometidas al arbitraje, se podrá dar reconocimiento y ejecución a las primeras; o d) Que la constitución del tribunal arbitral o el procedimiento arbitral no se han ajustado al acuerdo celebrado entre las partes o, en defecto de tal acuerdo, que la constitución del tribunal arbitral o el procedimiento arbitral no se han ajustado a la Ley del país donde se ha efectuado el arbitraje; o e) Que la sentencia no es aun obligatoria para las partes o ha sido anulada o suspendida por una autoridad competente del país en que, o conforme a cuya Ley, ha sido dictada esa sentencia. 2. También se podrá denegar el reconocimiento y la ejecución de una sentencia arbitral si la autoridad competente del país en que se pide el reconocimiento y la ejecución comprueba: a) Que, según la Ley de ese país, el objeto de la diferencia no es susceptible de solución por vía de arbitraje; o b) Que el reconocimiento o la ejecución de la sentencia serían contrarios al orden público de ese país" (“Convención de Nueva York", artículo V). 
jurídica. Para el laudo, tal declaratoria viene en la forma de una sentencia de anulación, que declara su invalidez si es que no hay duda razonable a favor de su validez. Pura teoría del derecho de conocimiento general positivada por la Convención, que al negar el reconocimiento a un laudo anulado en el lugar

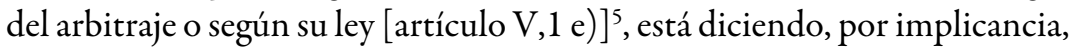
dos cosas: $i$ ) que solo la jurisdicción cuya ley otorga nacionalidad al laudo puede anularlo (i.e. que solo los tribunales de dicha jurisdicción primaria, de acuerdo a sus reglas de competencia, pueden anularlo); y $i i$ ) que ninguna otra jurisdicción puede anularlo. Así tomado, el artículo V,1,e) no solo regla una causal de denegación del reconocimiento, sino que, al hacerlo, devela su naturaleza de norma de competencia, haciendo que solo la jurisdicción primaria esté autorizada por la Convención para declarar la invalidez de un laudo. Y, puesto que toda norma de competencia es en sí misma excluyente de las autoridades normativas a las que no confiere poder, al conferirse el poder de anular el laudo a la jurisdicción primaria, quedan excluidas las jurisdicciones secundarias de poder hacerlo.

5. Por eso, cuando confrontada con laudos anulados en jurisdicciones secundarias, la jurisprudencia no ha dudado en reconocerlos.

a) Es el caso de un laudo estadounidense anulado en República Dominicana: "La Corte toma nota que "Nicor" y "Carib" parecen sugerir en un pié de página que el laudo arbitral no debiera ser reconocido, porque los tribunales dominicanos han denegado su reconocimiento. De acuerdo al artículo V,1 e) de la "Convención de Nueva York", la Corte no debe reconocer un laudo arbitral si el mismo fue anulado o suspendido por una autoridad competente del país en que, o conforme a cuya ley, fue dictado. Como el laudo arbitral no fue hecho en o bajo las leyes de la República Dominicana, la denegación de reconocimiento por parte de los tribunales dominicanos no es argumento para denegar el reconocimiento de acuerdo a la "Convención de Nueva York". El asunto "Baker Marine Ltd. v. Chevron Ltd." citado por "Nicor" es inaplicable al presente caso. Más aún, una decisión de esta Corte reconociendo la sentencia de las cortes dominicanas violaría claramente el orden público estadounidense que favorece al arbitraje" (Corte de Distrito de Florida, asunto "Nicor International Corporation/Carib Consult v. El Paso Corporation”, 2003)'.

5 “1. Solo se podrá denegar el reconocimiento y la ejecución de la sentencia, a instancia de la parte contra la cual es invocada, si esta parte prueba ante la autoridad competente del país en que se pide el reconocimiento y la ejecución: e) Que la sentencia no es aun obligatoria para las partes o ha sido anulada o suspendida por una autoridad competente del país en que, o conforme a cuya Ley, ha sido dictada esa sentencia" [“Convención de Nueva York", artículo V,1 e)].

${ }^{6} 292$ F. Supp.2d 1357 (2003). Fuente: http://www2.ambrac.nl/kli-ka-csg/document.aspx?id=ipn 26025 
b) Y es también el caso de un laudo suizo anulado en Indonesia: "La "Convención de Nueva York" proporciona un cuidadosamente estructurado marco para la revisión y ejecución de los laudos arbitrales. Sólo una corte de un país con jurisdicción primaria sobre un laudo puede anularlo. Las cortes de otros países son jurisdicciones secundarias: una corte de jurisdicción secundaria está limitada a decidir si el laudo puede ejecutarse en ese territorio. La Convención establece regímenes muy diferentes para la revisión de un laudo $i$ ) en los países en los que, o bajo cuya ley, el laudo fue hecho; y ii) en los países en los que se busca su reconocimiento y ejecución. Según la Convención, el país en el que, o conforme a cuya ley, el laudo fue dictado, tiene jurisdicción primaria sobre él. Todos los otros Estados signatarios de la Convención son jurisdicciones secundarias, en las que las partes pueden solamente controvertir si ese Estado debe o no ejecutar el laudo (párrafo 26)". "El artículo V específica los motivos por los cuales una corte con jurisdicción secundaria puede denegar el reconocimiento. En contraste con la limitada autoridad de las cortes de jurisdicciones secundarias para revisar un laudo arbitral, las cortes de la jurisdicción primaria, habitualmente las cortes del lugar del arbitraje, tienen una mucha mayor discreción para invalidar un laudo. Mientras que las cortes de la jurisdicción primaria pueden aplicar su propio derecho nacional para evaluar una solicitud de anulación de un laudo, las cortes de las jurisdicciones secundarias pueden denegar su reconocimiento solo por las razones tasadas en el artículo V (párrafo 27)". "El artículo V,1 e) de la Convención regla que una corte con jurisdicción secundaria puede rechazar la ejecución de un laudo arbitral si el mismo ha sido anulado o suspendido por una autoridad competente del país, o bajo cuya ley, el laudo fue hecho. La jurisprudencia ha sostenido que, al referirse a la autoridad competente del país, o bajo cuya ley, el laudo fue hecho, la Convención se refiere exclusivamente a la ley procesal y no a la sustantiva y, más precisamente, al régimen legal de procedimiento arbitral bajo el cual el arbitraje se condujo, y no al derecho sustantivo que se aplicó al caso (párrafo 30)". "De acuerdo a la "Convención de Nueva York", un acuerdo especificando el lugar del arbitraje crea una presunción en sentido que la legislación procesal de aquel lugar es la aplicable al arbitraje. Opiniones autorizadas en arbitraje internacional afirman que un acuerdo pactando que un país será el lugar del arbitraje, pero el procedimiento se conducirá bajo la legislación arbitral de otro país es 'excepcional', 'casi desconocido', 'una pura invención académica', 'casi nunca usado en la práctica', 'una posibilidad más teórica que real' y 'un raro evento que depende de muchas otras circunstancias'. Estas opiniones anotan que tal acuerdo sería 'complejo', 'inconveniente' e 'inconsistente' con la elección de un foro neutral como lugar del arbitraje (párrafo 32)". "Aunque un acuerdo arbitral puede elegir más de un país como jurisdicción 
primaria, la opinión predominante es que la Convención permite sólo uno para cada caso. 'Muchos doctrinarios y tribunales extranjeros han concluido que una acción para anular el laudo sólo puede ser demandada de acuerdo al derecho nacional del foro arbitral'. El experto en arbitraje internacional de "Pertamina" presentó un informe a la Corte de Distrito afirmando que 'solo puede haber un solo país cuyas cortes sean competentes para anular el laudo'. Esa jurisdicción primaria exclusiva de los tribunales de un solo país es coherente con el propósito de la "Convención de Nueva York"” (párrafo 106). "De acuerdo con la "Convención de Nueva York", el acuerdo arbitral de las partes y el expediente arbitral, Suiza tuvo jurisdicción primaria sobre el laudo. Ya que Indonesia no tiene jurisdicción primaria para invalidar el laudo, esta Corte confirma la decisión de la Corte de Distrito en sentido que la anulación dictada por un tribunal indonesio no es defensa para evitar la ejecución del laudo al amparo de la "Convención de Nueva York" (párrafo 109)" (todo en Corte de Apelaciones del Quinto Circuito de Estados Unidos, asunto "Karaha Bodas Co. v. Preusan Pertambangan Minyan Dan Gas Bumi Negara, et al.", 2004) ${ }^{7}$.

\section{RECONOCIMIENTO DE LAUDOS ANULADOS POR SUS JURISDICCIONES PRIMARIAS}

\section{Aplicación del derecho más favorable.}

a) La jurisprudencia ha reconocido laudos anulados por sus jurisdicciones primarias con pie en dos fundamentos: $i)$ por aplicación del derecho más favorable; y ii) porque la decisión de anulación es contraria al orden público. El primer fundamento no es tal. Como se verá, descansa sobre una petición de principio. Que en su auxilio no pueda oponer siquiera a la lógica formal revela su endeblez.

Ya está dicho que un laudo anulado por su jurisdicción primaria no puede ser reconocido en ninguna jurisdicción secundaria. Es pura consecuencia de la inexistencia jurídica que comporta la declaratoria de anulación [artículo V,1 e)] de la "Convención de Nueva York"). Pero tribunales franceses y estadounidenses han dicho lo contrario.

i) Los primeros reconocieron un laudo anulado en Austria: "Ya que el artículo VII de la Convención [de Nueva York] no priva a ninguna parte interesada de ningún derecho que pudiese tener a hacer valer un laudo en la forma y medidas admitidas por la legislación o los tratados del país donde dicho laudo se invoque, un juez no puede denegar el reconocimiento cuando su propia legislación nacional le permite hacerlo, y, por virtud del artículo

${ }^{7} 364$ F.3d 274. Fuente: http://caselaw.findlaw.com/us-5th-circuit/1207034.html 
12 del nuevo Código Procesal Civil, él debe, aún ex officio, indagar sobre el asunto si tal es el caso" (Corte de Casación de Francia, asunto "Société Pabalk Ticaret Ltd. v. Société Norsolor", 1984) ${ }^{8}$. Y también reconocieron un laudo anulado en Suiza: "'Hilmarton' argumenta que la sentencia apelada (París, 19 de diciembre de 1991) confirma el exequátur a pesar de que el laudo ha sido anulado. De acuerdo con la apelación de 'Hilmarton', tal cosa no es posible en aplicación de los artículos 15 y 16 de la Convención Franco-Suiza de 15 de junio de 1869. Además, ya que tales disposiciones son menos favorables al reconocimiento de laudos que aquellas de la "Convención de Nueva York", esta última debe aplicarse, especialmente su artículo V,1e), según el cual el reconocimiento y ejecución debe ser denegado cuando el laudo ha sido anulado en el lugar de su dictado. Más aún, la Corte de Apelaciones violó los artículos 1498 y 1502.5 del nuevo Código Procesal Civil, al reconocer efectos a un laudo que ha sido anulado y, por tanto, privado de su existencia legal". "Primero que todo, la Convención Franco-Suiza de 1869 es inaplicable, debido a que la misma cesó en su vigor el 1 de enero de 1992". "Más aún, la decisión a quo correctamente sostiene, aplicando el artículo VII de la "Convención de Nueva York", que OTV puede apoyarse en la legislación francesa sobre arbitraje internacional concerniente al reconocimiento y ejecución de laudos arbitrales dictados en el extranjero y, especialmente, en el artículo 1502 del nuevo Código Procesal Civil, que no regula las causales previstas por el artículo $\mathrm{V}$ de la Convención como causales para denegarles el reconocimiento y ejecución". "Por último, el laudo dictado en Suiza es un laudo internacional que no forma parte del sistema jurídico suizo, por lo que continúa existiendo aún si anulado y su reconocimiento en Francia no es contrario al orden público internacional" (Corte de Casación de Francia, asunto "Hilmarton Ltd. v. OTV", 1997) 9

ii) Y los tribunales estadounidenses, además de los franceses, reconocieron un laudo anulado en Egipto: "Mientras que el artículo V proporciona un estándar discrecional, el artículo VII de la Convención requiere que las disposiciones de la Convención no priven a ninguna parte interesada de ningún derecho que pudiese tener a hacer valer un laudo en la forma y medidas admitidas por la legislación o los tratados del país donde dicho laudo se invoque. En otras palabras, de acuerdo a la Convención, Chromalloy Aeroservices mantiene los mismos derechos para ejecutar este laudo que hubiese tenido en ausencia de la Convención. Consecuentemente, la Corte encuentra que, si la Convención no existiese, la Ley Federal de Arbitraje proporcionaría a

\footnotetext{
${ }^{8}$ Fuente: http://www.uchastings.edu/faculty administration/faculty/armbruster/ Case5_CourdeCassation.pdf

${ }^{9}$ Fuente: http://www2.ambrac.nl/kli-ka-csg/document.aspx?id=ipn5493
} 
Chromalloy el legítimo derecho de ejecutar este laudo". "Como la Corte ha ya explicado, el artículo $\mathrm{V}$ proporciona un estándar permisivo, a partir del cual esta Corte puede denegar la ejecución de un laudo. El artículo VII, en cambio, obliga a que esta Corte deba considerar la petición de Chromalloy de acuerdo a la legislación estadounidense aplicable" (Corte de Distrito de Columbia, asunto "Chromalloy Aeroservices v. Egipto", 1996) ${ }^{10}$.

En resumen: $i$ ) Todos estos laudos habían sido anulados en sus respectivas jurisdicciones primarias; ii) Para reconocerlos, los respectivos tribunales echaron mano del artículo VII de la Convención, que permite aplicar las normas internacionales o internas más favorables al reconocimiento; iii) Sobre esa base razonaron que el Código Procesal Civil en Francia y la Ley federal de arbitraje en Estados Unidos eran más favorables al reconocimiento que la Convención, debiendo aplicarlas en cumplimiento de ella.

La falacia salta a la vista. Se trata de una petición de principio. Acá los tribunales han presupuesto la verdad de lo que tenían que demostrar. No está en discusión que el artículo VII favorezca el reconocimiento ${ }^{11}$, sino si puede aplicarse una Convención sobre reconocimiento de laudos a laudos que, según ella misma, son jurídicamente inexistentes por haber sido anulados en sus respectivas jurisdicciones primarias [artículo V,1 e)]. Al eludir esta pregunta, la jurisprudencia pone en entredicho su corrección racional. Para la teoría del derecho, hay corrección racional cuando las decisiones son justificables por su universalidad, su coherencia y su consecuencia con los valores del sistema ${ }^{12}$. Y son coherentes, en lo que respecta a sus premisas normativas, cuando su justificación no es antinómica con otras normas también aplicables. Y acá está el problema: al reconocer laudos anulados en sus jurisdicciones primarias con fundamento en el artículo VII de la Convención, se ha aplicado dicho artículo en forma antinómica con su artículo $\mathrm{V}, 1 \mathrm{e})$, que, más bien, para el mismo supuesto fáctico dispone la denegatoria del reconocimiento.

b) No mucho después, los tribunales estadounidenses recondujeron su jurisprudencia.

${ }^{10} 939$ F. Supp. 907. Fuente: http://law.queensu.ca/international/globalLawProgramsAtTheBISC/courseInfo/courseOutlines/commercialArbitration2010/chromalloyVEgypt.pdf

11 "Las disposiciones de la presente Convención no afectarán la validez de los acuerdos multilaterales o bilaterales relativos al reconocimiento y la ejecución de las sentencias arbitrales concertados por los Estados contratantes, ni privarán a ninguna de las partes interesadas de cualquier derecho que pudiera tener a hacer valer una sentencia arbitral en la forma y medida admitidas por la legislación o los tratados del país donde dicha sentencia se invoque" ("Convención de Nueva York", artículo VII,1).

${ }^{12}$ Cf. MacCormick, Neil, Legal Reasoning and Legal Theory (1 $1^{a}$ edición, Nueva York, Clarendon Press, 1978). 
i) Se negaron a reconocer un laudo anulado en Nigeria: "Baker Marine argumenta que la decisión de la Corte de Distrito no aplicó el artículo VII de la Convención, que dispone que la misma no privará a ninguna parte interesada de ningún derecho que pudiese tener a hacer valer un laudo en la forma y medidas admitidas por la legislación o los tratados del país donde dicho laudo se invoque. Baker Marine afirma que los laudos fueron anulados por las cortes nigerianas por motivos no previstos en la legislación estadounidense como válidos para invalidar un laudo y que, de acuerdo al artículo VII, puede invocar la legislación de este país, a pesar de la actuación de las cortes nigerianas". "Rechazamos este argumento. Es suficiente respuesta al mismo el hecho que las partes hubiesen contratado en Nigeria que sus controversias serían arbitradas de acuerdo a las leyes nigerianas. El acuerdo entre ellas no hace ninguna referencia a los Estados Unidos. Nada sugiere que hubiese sido la intención de las partes que la legislación estadounidense regule sus disputas. El principal propósito de la Ley Federal de Arbitraje es asegurar que los convenios arbitrales se aplique de acuerdo a sus propios términos. Baker Marine no ha controvertido que las cortes nigerianas hubiesen actuado en contra de su ley" (Corte de Apelaciones del Segundo Circuito de Estados Unidos, asunto "Baker Marine v. Chevron", 1999)" ${ }^{13}$.

ii) Y se negaron también a reconocer un laudo anulado en Italia: "Spier busca aplicar la legislación arbitral estadounidense para eludir la sentencia italiana de anulación del laudo. Ese esfuerzo no puede superar la observación de la Corte de Apelaciones en el asunto "Yusuf", en sentido que en el marco de la Convención [de Nueva York] el Estado en el cual, o bajo cuyas leyes, el laudo fue dictado sería libre de anularlo o modificarlo de acuerdo con su legislación nacional y toda su panoplia de medios expresos e implícitos de reparación. En este caso, el laudo fue anulado por el más alto tribunal del Estado, la Corte de Casación de Italia. Ninguna corte americana o ley puede ser citada en sentido [de desconocer tal decisión]. En otras palabras, Spier no puede argumentar que las decisiones de los tribunales italianos no deben ser reconocidas, porque una corte americana llegaría a un resultado diferente respecto al laudo, si es que el mismo hubiese sido dictado en los Estados Unidos" (Corte de Distrito del Distrito Sur de Nueva York, asunto "Spier v. Calzaturificio Tecnica", 1999) $)^{14}$.

c) Jurídicamente, esto es lo correcto. Pero dice Park que un laudo anulado en su jurisdicción primaria podría ser reconocido en dos casos: $i$ ) cuando se presumiese que los tribunales de la jurisdicción primaria son corruptos

\footnotetext{
${ }^{13}$ Fuente: http://caselaw.findlaw.com/us-2nd-circuit/1011705.html

${ }^{14} 71$ F. Supp. $2 d 279$ (1999). Fuente: http://www.leagle.com/xmlResult.aspx?xml doc=199935071FSupp2d279_1323.xml\&docbase=CSLWAR2-1986-2006
} 
o carecen de la imparcialidad suficiente; y ii) cuando el laudo hubiese sido anulado por causales propias de la ley del lugar del arbitraje que, por ser manifiestamente contrarias al derecho comparado, no reconocerlo supusiese atentar contra la eficacia del arbitraje internacional. Para fundar ambas hipótesis se apoya en el texto común del artículo V,1, que, según la lectura que de él hace, al decir que se "podrá" denegar el reconocimiento, estaría diciendo que es potestativo denegarlo ${ }^{15}$.

Ambas opciones deben descartarse.

i) La primera, porque los tribunales de un Estado no son competentes para pronunciarse sobre la probidad e imparcialidad de sus pares de otro Estado. Tratándose de decisiones de los órganos internos de un Estado, para que los órganos internos de otro se pronunciasen sobre ellas debiera haber entre los Estados involucrados un regla de derecho internacional que confiriese a los tribunales del segundo Estado una competencia en tal sentido. Tal regla no existe. Pero sí la contraria, que es el propio artículo V,1 e) de la Convención, que establece la denegación del reconocimiento por razón de la anulación del laudo en la jurisdicción primaria. Por tanto, reconocer un laudo anulado en su jurisdicción primaria es, formalmente, una actuación arbitraria de la jurisdicción secundaria, por contraria a dicho artículo. Comporta la responsabilidad internacional del Estado, por la actuación de sus tribunales en quebrantamiento de la regla pacta sunt servanda. Pero, además, que un tribunal extranjero pudiese pronunciarse sobre la moralidad de sus pares, contraría la lógica que informa al reconocimiento. Reconocer una decisión extranjera es un puro acto formal. En cambio, pronunciarse sobre la moralidad de los tribunales extranjeros para, a cubierto de su inmoralidad, reconocer el laudo anulado por ellos, es un acto de juzgamiento en su más puro sentido valorativo: para que revistiese visos de juridicidad, habría que probar la relación de causalidad entre la inmoralidad del tribunal y la anulación del laudo. Tamaña labor exorbita largamente la idea misma de reconocimiento. A una crítica de juridicidad, tal cosa significa contestar una arbitrariedad con otra.

ii) La segunda opción debe descartarse porque contraría el fundamento mismo del arbitraje. El arbitraje es consecuencia de la libertad de disposición que tienen los particulares sobre sus derechos negociables. Si en su ejercicio deciden someter su controversia a un arbitraje regido por una legislación inamigable, así como debe respetarse la forma que eligieron para resolver sus controversias, debe respetarse también la elección que hicieron del lugar

${ }^{15}$ Cf. PARK, William, Duty and Discretion in International Arbitration, en American Journal of International Law, 93 (1999), pp. 805 y 810. 
del arbitraje. Respetar lo primero y no lo segundo sería institucionalizar el cumplimiento a conveniencia de las normas.

iii) $\mathrm{Y}$ ambas opciones en conjunto deben descartarse porque, al decir "podrá", el artículo V,1 no está diciendo que la denegación del reconocimiento esté librada a la discreción de los tribunales del Estado del foro, por tres razones, una teleológica y dos gramaticales. La teleológica: si ese fuera su significado, entonces la propia Convención caería por su base: que una convención cuyo objeto y fin es facilitar el reconocimiento, reglando ella misma las causales taxativas para su denegación, permitiese la aplicación discrecional de dichas causales, supondría que ella misma se vaciase de contenido. Con lo cual su ineficacia quedaría garantizada. Las razones gramaticales son que: i) En consecuencia con el telos de la Convención, el artículo $V$ abre su texto con el adverbio "solo", que significa "únicamente". Y si el significante dice "[únicamente] se podrá denegar el reconocimiento y ejecución [por las causales listadas]", entonces su significado es que no se puede denegar el reconocimiento por ninguna otra causal; y que tampoco se puede reconocer un laudo cuando una causal de denegatoria ha sido probada. Y esto excluye, desde el propio significado convencional del lenguaje empleado, que el mismo sea fuente de poder discrecional alguno para los tribunales del Estado del foro (al menos como no sea haciendo una interpretación contra-literal, donde "solo" no signifique lo que convencionalmente es aceptado que significa: "únicamente). Al contrario, al decir "solo se podrá", se está limitando la competencia judicial en la materia a las causales tasadas por el artículo $\mathrm{V}$ (primer argumento gramatical). ii) Hasta acá lo que el artículo V no norma, ahora lo que sí: tomado el artículo $V$ en su integridad, la posibilidad de denegar el reconocimiento, referida en su parágrafo 1 , está atada a que, la parte que se opone al mismo, demande y pruebe la causal invocada (textualmente dice "a instancia de la parte contra la cual es invocada" y "si esta parte prueba", respectivamente), lo cual hace sentido cuando contrastado con el parágrafo 2, que, al decir "también se podrá denegar el reconocimiento" y no requerir ni la demanda ni la prueba de parte, está diciendo que las causales por él contempladas pueden operar de oficio. Por tanto, como en el parágrafo 1 la denegación depende del pedido y la prueba que produzca la parte que se opone al reconocimiento, al decir "podrá", la Convención no se está dirigiendo a los tribunales, sino a dicha parte, a la cual le está diciendo que puede defenderse probando que el laudo está incurso en una de las causales tasadas por ella. Y todo esto dicho en disenso con la jurisprudencia, que interpreta, más bien, que el artículo V,1 tiene carácter potestativo: "Esta Corte debe conceder la petición de Chromally Aeroservices de reconocer y ejecutar el laudo arbitral, salvo que se encuentre ante una causal de denegatoria especificada en la Convención [de Nueva York]. Bajo la Convención, el reconocimiento 
y ejecución de un laudo puede ser denegado si Egipto suministra prueba de que el laudo ha sido anulado por una autoridad competente del país, o bajo cuya ley, el laudo fue hecho [artículo V,1 e)]. Por tanto, la Corte puede, a su discreción, denegar el reconocimiento del laudo" (Corte de Distrito de Columbia, asunto "Chromalloy Aeroservices v. Egipto", 1996) ${ }^{16}$.

Que las causales propias de anulación de una determinada legislación arbitral fuesen manifiestamente contrarias al derecho comparado es asunto que debe solucionarlo el derecho internacional. Ya de esto se tiene el antecedente en el Convenio europeo sobre arbitraje comercial internacional (1961). $\mathrm{Su}$ artículo IX,1 tasa las causales de anulación por las que se denegará el reconocimiento, y su artículo IX,2 restringe la aplicación del artículo $\mathrm{V}, 1 \mathrm{e}$ ) de la "Convención de Nueva York" a las causales de anulación tasadas en el primer parágrafo ${ }^{17}$. El resultado: un régimen común de anulación para los laudos que fueran a ejecutarse en el extranjero ${ }^{18}$ (nótese que la Convención

${ }^{16}$ En nota 10.

17 "1. La anulación en uno de los Estados contratantes de un laudo arbitral amparado por el presente Convenio constituirá causa de denegación en lo referente al reconocimiento o ejecución de dicho laudo en otro Estado contratante, sólo en el caso de que tal anulación se hubiere llevado a efecto en aquel Estado en el cual o conforme a cuya ley fue pronunciado el fallo arbitral y ello por una de las siguientes razones: a) Las partes en el acuerdo o compromiso arbitral estaban, con sujeción a la ley a ellas aplicable, afectadas de una incapacidad de obrar, o dicho acuerdo o compromiso no era válido con arreglo a la ley a la cual lo sometieron las partes o, en caso de no haber indicación al respecto, conforme a la ley del país en donde se dictó el laudo; o b) La parte que pide la anulación del laudo no había sido informada debidamente sobre el nombramiento del árbitro o sobre el desarrollo del procedimiento arbitral, o le había sido imposible, por cualquier otra causa hacer valer sus alegaciones o recursos; o c) El laudo se refiere a una controversia no prevista en el compromiso arbitral o no incluida dentro de lo establecido en la cláusula compromisoria; o contiene decisiones sobre materias que sobrepasen los términos del compromiso arbitral de la cláusula compromisoria, entendiéndose, empero, que si las resoluciones del laudo que versen sobre cuestiones sometidas al arbitraje, puedan ser separadas o disociadas de aquellas otras resoluciones concernientes a materias no sometidas al arbitraje, las primeras podrán no ser anuladas, o d) La constitución o composición del tribunal de árbitros o el procedimiento arbitral no se ha ajustado al acuerdo o compromiso entre las partes o, no habiendo existido tal acuerdo o compromiso, a lo establecido en el artículo IV del presente Convenio. 2. En las relaciones entre aquellos Estados contratantes que sean al mismo tiempo Partes en el Convenio de Nueva York de 10 de junio de 1958 sobre Reconocimiento y Ejecución de Sentencias Arbitrales Extranjeras, el párrafo $1^{\circ}$ del presente artículo viene a restringir la aplicación del artículo V, párrafo 1. e) del Convenio de Nueva York únicamente en los casos de anulación expuestos en dicho párrafo $1^{\circ}$ " (Convenio europeo sobre arbitraje comercial internacional, artículo IX).

${ }^{18}$ La idea no es original. Cf. DAvis, Kenneth R., Unconventional Wisdom: A New 
no prohíbe a los Estados legislar otras causales, que pueden hacerlo, sino que les niega efectos en el extranjero).

\section{Decisión de anulación contraria al orden público.}

a) En el asunto "Chromalloy", el laudo anulado en Egipto (jurisdicción primaria) fue reconocido en Estados Unidos por dos razones: la primera, la aplicación del derecho más favorable (de juridicidad dudosa por apoyarse en una petición de principio); la segunda, que la decisión de anulación del laudo contrariaba el orden público. Este último fundamento fue utilizado también en los asuntos "Baker Marine" y "Spier”, para justificar que, al no ser las decisiones de anulación contrarias al orden público, los laudos anulados no merecían ser reconocidos. Con este mismo propósito fue utilizado en “TermoRío SA ESP” y "LeaseCo Group LLC v. Electranta SP” (Corte de Apelaciones del Circuito del Distrito de Columbia, 2007), para, finalmente, aplicarlo en el asunto "Corporación Mexicana de Mantenimiento Integral SRL v. PEMEX-Exploración y Producción", que reconoció un laudo mexicano anulado en su jurisdicción primaria (Corte de Distrito del Distrito Sur de Nueva York, 2013). Que este último caso aplique la Convención interamerican a sobre arbitraje comercial internacional (Panamá, 1975) en vez de la de Nueva York no cambia en nada las cosas, por la identidad de sus textos.

b) Esta es la jurisprudencia, en sus propios textos:

i) "En los Estados Unidos, 'hace tiempo que superamos la época en la que la suspicacia judicial frente al arbitraje inhibía el desarrollo de éste como método alterno de resolución de disputas' ("Mitsubishi Motors Corp. v. Soler Chrysler-Plymouth Inc”). En Egipto, en cambio, 'está establecido que el arbitraje es un medio excepcional de resolución de conflictos, alejado de los medios judiciales tradicionales y de las garantías que ellas prestan' (Decisión de Anulación). Egipto afirma que el laudo arbitral es nulo de acuerdo a ley arbitral, porque no fue debidamente fundado en el derecho egipcio. Esta afirmación refleja sus suspicacias respecto al arbitraje y es precisamente el tipo de argumento técnico en el que las cortes americanas no entramos cuando revisamos un laudo". "La Corte considera ahora si la decisión egipcia [anulando el laudo] debe ser reconocida como una sentencia extranjera válida. Como la Corte dijo antes, este es un caso hito. No ha habido casos en los que una corte de los Estados Unidos enfrente una situación, bajo la Convención, en la cual la corte de una nación extranjera ha anulado un laudo que de otro modo sería válido". "El orden público estadounidense a favor del arbitraje vinculante y final en controversias comerciales es inequívoco

Look at Articles V and VII of the Convention on the Recognition and Enforcement of Foreign Arbitral Awards, en Texas International Law Journal, 37 (2002), p. 84. 
y fundado en tratados, leyes y jurisprudencia. La Ley Federal de Arbitraje y la implementación de la Convención el mismo año por enmienda de dicha Ley, demuestran que hay una enfática política federal a favor del arbitraje, particularmente en el campo del comercio internacional. Una decisión de esta Corte que reconociese la decisión del tribunal egipcio violaría el claro orden público estadounidense al respecto". "La Corte concluye que el laudo arbitral es válido en lo que respecto al derecho estadounidense. La Corte, además, concluye que no necesita conferir efectos de cosa juzgada a la sentencia egipcia de la Corte de Apelación de El Cairo" (Corte de Distrito de Columbia, asunto "Chromalloy Aeroservices v. Egipto", 1996) ${ }^{19}$.

ii) "Baker Marine presenta un último argumento, basado en el lenguaje del artículo V,1 e) de la Convención. Dice este artículo que cuando una parte pretende el reconocimiento de un laudo, su reconocimiento y ejecución 'puede' ser denegado si es que el mismo ha sido anulado por una autoridad competente del país en el cual el laudo fue dictado. Baker Marine sostiene que el uso de un vocablo permisivo, 'puede', en vez de un término imperativo, implica que se puede ejecutar el laudo, a pesar de la sentencia nigeriana anulándolo. Es suficiente respuesta a esto el hecho que Baker Marine no hubiese mostrado ninguna razón adecuada para rechazar el reconocimiento de las sentencias de la corte nigeriana" (Corte de Apelaciones del Segundo Circuito de Estados Unidos, asunto "Baker Marine v. Chevron", 1999)20.

iii) "La referencia que hace Spier, en sentido que al decir 'puede' el artículo V,1 de la Convención está siendo permisivo, no le asiste, ya que, tal como ocurrió en Baker Marine, Spier tampoco ha mostrado una razón adecuada para no reconocer las sentencias dictadas por las cortes italianas". "Por último, la decisión de la Corte de Distrito en "Chromalloy" de aplicar la Ley Federal de Arbitraje para apartar una sentencia egipcia anulatoria de un laudo también egipcio, se fundó en una circunstancia particular ausente en el presente caso: la descarada indiferencia de Egipto respecto a su obligación contractual de no apelar contra el laudo arbitral. Spier no señala ninguna disposición comparable con aquella en su contrato con Tecnica y, mientras que Spier deplora las decisiones de las cortas italianas, él no sugiere siquiera que la legislación nacional italiana, aplicable a este laudo italiano por virtud de la Convención, tal como fue interpretada por el Segundo Circuito en "Yusuf", no autorizase a Tecnica a controvertir el laudo en las cortes italianas". "Sólo queda decir, en forma contraria a la conclusión previamente dicha, que si Spier tiene derecho a examinar este laudo de acuerdo a las disposiciones de la legislación estadounidense, tal derecho no le otorgaría nada. Esto es así

\footnotetext{
${ }^{19}$ En nota 10.

${ }^{20}$ En nota 13 .
} 
porque las tres cortes italianas anularon el laudo porque al hacerlo los árbitros excedieron su competencia, lo cual también es un motivo de anulación en la legislación estadounidense" (Corte de Distrito del Distrito Sur de Nueva York, asunto "Spier v. Calzaturificio Tecnica", 1999)21.

iv) "Resolvemos este asunto refiriéndonos y aplicando la "Convención de Nueva York” (párrafo 26)". "La regla básica de la Convención es que 'cada Estado parte reconocerá la autoridad de los laudos arbitrales y los ejecutará de conformidad con las normas de procedimiento vigentes en el Estado en el cual el laudo fuera invocado' (párrafo 29)". "De acuerdo a la Convención, sólo la corte de un país con jurisdicción primaria sobre el laudo puede anularlo (párrafo 41)”. De conformidad con el artículo V,1 e) de la Convención, una Estado con jurisdicción secundaria normalmente no puede ejecutar un laudo que haya sido anulado en su jurisdicción primaria por una autoridad competente. Ya que el Consejo de Estado es innegablemente una autoridad competente en Colombia (el Estado con jurisdicción primaria),y ya que no hay nada en el expediente indicando que el procedimiento ante el Consejo de Estado estuviese viciado o que la decisión de dicho órgano no es auténtica, Electranta afirma que TermoRío no tiene argumentos bajo la Ley Federal de Arbitraje o la Convención para ejecutar el laudo. De acuerdo a lo obrado, estamos de acuerdo (párrafo 46)". "Para nosotros, respaldar lo que TermoRío busca erosionaría seriamente un principio rector de la Convención: un laudo arbitral no existe para ser ejecutado en otros Estados parte si es que el mismo ha sido legalmente anulado por una autoridad competente del Estado en el cual fue dictado. Este principio gobierna este caso (párrafo 49)". "TermoRío va muy lejos al sugerir que un tribunal en una jurisdicción secundaria es libre de ignorar la decisión de anulación de una autoridad competente de la jurisdicción primaria. Se requiere mucho más que una mera afirmación diciendo que la sentencia de la jurisdicción primaria ofende el orden público de la jurisdicción secundaria para superar una defensa fundada en el artículo V, 1 e) (párrafo 54)". "Al aplicar el artículo V,1 e) de la Convención, debemos ser muy cuidadosos al ponderar las nociones de orden público para determinar la validez de una sentencia de anulación pronunciada por una autoridad competente de la jurisdicción primaria. El examen de orden público no puede limitarse simplemente a determinar si los tribunales de la jurisdicción secundaria hubiesen anulado un laudo si es que el mismo hubiese sido dictado en ella. Como ya se lo notó, la Convención contempla que diferentes Estados parte puedan tener diferentes causales de anulación de laudos. Por tanto, no es de sorprender que las cortes tengan

${ }^{21}$ En nota 14. http://www.leagle.com/xmlResult.aspx?xmldoc=199935071FSupp 2d279_1323.xml\&docbase $=$ CSLWAR2-1986-2006 
limitadas ocasiones para ignorar una sentencia extranjera por motivos de orden público (párrafo 56)". "Una sentencia no es ejecutable por razones de orden público si es que es repugnante a las nociones fundamentales de lo que es decente y justo en el Estado en el que se persigue su reconocimiento. En su formulación clásica, una sentencia que claramente tiende a minar el interés público, la confianza pública en la administración de la ley o la seguridad de los derechos a la libertad o la propiedad es contraria al orden público (párrafo 57)". "Aceptando que hay un tenue brillo de orden público en el artículo V,1 e) de la Convención y que una sentencia extranjera es inejecutable por contraria al orden público si la misma es contraria a las nociones fundamentales de decencia y justicia en los Estados Unidos, TermoRío no ha alegado ni producido pruebas que sugieran que el procedimiento ante el Consejo de Estado de Colombia o su decisión viole las nociones básicas de justicia que adherimos (párrafo 64)" (Corte de Apelaciones del Circuito del Distrito de Columbia, asunto "TermoRío SA ESP y LeaseCo Group LLC v. Electranta SP", 2007) ${ }^{22}$.

v) "Por lo general, los laudos arbitrales dictados en un Estado pueden ser ejecutados por las cortes de otros Estados. Sin embargo, los laudos pueden también ser anulados, y si fueron anulados por las cortes del país, o bajo cuya ley, fueron dictados, se origina un conflicto para las cortes de los otros Estados. ¿A cuál deben dar primacía, al laudo o a la sentencia que lo anula?”. "PEMEX-Exploración y Producción (PEP) tuvo éxito en las cortes mexicanas. El 21 de septiembre de 2011 la Décimo Primera Corte Colegiada en lo Civil del Distrito Federal (la Décimo Primera Corte Colegiada) dictó una sentencia de 486 páginas sosteniendo que el laudo era inválido. Revirtió la decisión de la Corte de Distrito mexicana y le reenvió el caso para que dicte una sentencia a favor de PEP. El 25 de octubre de 2011, la Corte de Distrito dictó tal sentencia en una decisión de 46 páginas". "La Décimo Primera Corte Colegiada sostiene que los árbitros no son competentes para decidir un caso en contra de entes soberanos o contra agentes de ellos y que la sede adecuada para una contraparte agraviada por una relación comercial es la Corte del Distrito en lo Administrativo de México. De ahí que anulase el laudo. Dicha corte fundamentó su sentencia en parte en una ley que no estaba en vigor a tiempo del contrato y tal decisión dejó a la Corporación Mexicana de Mantenimiento Integral (COMMISA) sin la posibilidad de obtener un juicio sobre el fondo del asunto". "Sostengo, por las razones indicadas a continuación, que [al hacer esto] la decisión de la Décimo Primera Corte

22487 F. 3d 928. Fuente:

http://www.cadc.uscourts.gov/internet/opinions.nsf/3EA9064DC31B165A852 574400045448F/\$file/06-7058a.pdf 
Colegiada de México violó nociones básicas de justicia. Por tanto, rechazo el reconocimiento de la sentencia de la Décimo Primera Corte Colegiada y confirmo el reconocimiento del laudo". "De acuerdo al artículo 5 de la Convención de Panamá, puedo denegar el reconocimiento al laudo si PEP puede demostrar que una autoridad competente de México lo anuló. Claramente, la Décimo Primera Corte Colegiada es una autoridad competente. El asunto que debe decidirse es el significado de 'puede' denegar el reconocimiento. En otras palabras, chasta dónde llega mi poder discrecional como Juez de Distrito de los Estados Unidos para reconocer un laudo que ha sido anulado por un Estado extranjero". "El asunto "Chromalloy" sigue vigente, ya que tanto Baker Marine como TermoRio reconocieron que una Corte de Distrito podría dudar si reconocer una sentencia si la misma contradecía con las nociones básicas de justicia”. "En 'TermoRío' se dio una definición más sustancial de la discreción judicial en materia de reconocimiento: 'si la sentencia de anulación es contraria a las nociones fundamentales de decencia y justicia de Estados Unidos' o 'si la sentencia violó las nociones básicas de justicia a las cuales adherimos', entonces no debe ser aplicada". "Encuentro que bajo el estándar anunciado en 'TermoRío' la sentencia de anulación viola las nociones básicas de justicia y reconocerla no es una obligación”. "El centro de la disputa ante mí es la aplicación retroactiva de las leyes y la injusticia asociada que conlleva. Nociones elementales de justicia dictan que las personas deben tener la oportunidad de saber cuál es el derecho vigente y de adecuar su conducta a él. Por esta razón, el principio de que las consecuencias jurídicas de las conductas deben ser juzgadas por la ley vigente a tiempo de su producción tiene una inveterada y universal aplicación. En una sociedad libre y dinámica, la creatividad comercial y artística es fomentada por el Estado de Derecho que otorga a las personas confianza respecto de la ley". "Acá, la ley a tiempo del contrato daba a commisa la legítima expectativa de que su controversia podía ser arbitrada". "En este caso, la aplicación retroactiva de la ley fue hecha para beneficiar a una empresa pública sobre una contraparte privada. Hay un principio básico de justicia: si un ente soberano ha dejado su inmunidad y ha acordado contratar con un particular, la corte que conozca la controversia sobre el contrato debe tratar a ambas partes como iguales". "Aplicar una ley que entró en vigor tiempo después de que las partes celebraron el contrato era problemático. Pero esta sensación de injusticia fue exacerbada por el hecho que la decisión de la Décimo Primera Corte Colegiada dejó a COMMISA sin alternativa para litigar sobre el asunto que los árbitros habían resuelto a su favor". "[Dicha Corte] dijo que el caso en su integridad no era materia de arbitramento por razones de orden público. Fue una decisión que iba en contra del propio acuerdo celebrado por PEP, la ley de creación de pemex y las leyes de México a tiempo del contrato y de haber comenzado 
el arbitraje". "Al rechazar aplicar la decisión de la Décimo Primera Corte Colegiada, no se está decidiendo ni revisando la ley mexicana. Mi decisión no se basa en los méritos sustantivos de una particular ley mexicana, sino en su aplicación a hechos que sucedieron antes de su adopción. El momento en el que COMMISA demandó a PEP no había ley, jurisprudencia, ni ninguna otra fuente del derecho que le hiciese saber que debía iniciar su reclamación en la jurisdicción ordinaria y no en un arbitraje. COMMISA razonablemente creyó que estaba autorizada a arbitrar la controversia y la decisión de la Décimo Primera Corte Colegiada intempestivamente interrumpió esta razonable expectativa, aplicando una ley que no estaba vigente a tiempo del contrato $\mathrm{y}$, por tanto, denegando a COMMISA la oportunidad de tener un juicio sobre el fondo del asunto. Tal decisión viola las nociones básicas de justicia [de los Estados Unidos]" (Corte de Distrito del Distrito Sur de Nueva York, asunto "Corporación Mexicana de Mantenimiento Integral SRL v. PEMEXExploración y Producción”, 2013) ${ }^{23}$.

c) Hasta acá la jurisprudencia. En resumen: i) Los laudos anulados por sus jurisdicciones primarias no pueden ser reconocidos por las jurisdicciones secundarias, por regla del artículo V,1 e); ii Pero, a título de excepción, pueden ser reconocidos si las decisiones que los anularon violasen el orden público de la jurisdicción secundaria; iii) porque el texto común del artículo $\mathrm{V}, 1$, al decir que se "podrá" denegar el reconocimiento, está diciendo que es potestativo denegarlo. Este razonamiento es inocuo para el concepto jurídico de validez. La razón: en naturaleza jurídica no se trata de reconocer un laudo anulado, sino de denegar el reconocimiento a la sentencia de anulación. Como el laudo y la sentencia que lo anula son ambos decisiones extranjeras, para que produzcan sus efectos deben ser ambos reconocidos por el Estado del foro. Al reconocerse el laudo, pero no la sentencia que lo anula, ésta no despliega sus efectos invalidatorios en la jurisdicción secundaria, ante la cual el laudo es plenamente válido. Estoy de acuerdo con el fundamento (el orden público), pero no con su fuente (el artículo $\mathrm{V}, 1$ ).

d). No estoy de acuerdo con la fuente, porque, como ya dije, sostengo que, al decir "podrá", el artículo V,1 no está diciendo que la denegación del reconocimiento esté librada a la discreción de los tribunales del Estado del foro. Las razones ya dadas: $i$ ) Si ese fuera su significado, entonces la propia Convención caería por su base: que una convención cuyo objeto y fin es facilitar el reconocimiento, reglando ella misma las causales taxativas para su denegación, permitiese la aplicación discrecional de dichas causales, su-

${ }^{23} 10$ Civ. 206 (AKH). Fuente:

https://lettersblogatory.com/wp-content/uploads/2013/09/gov.uscourts. nysd_.357027.160.0.pdf 
pondría que ella misma se vaciase de contenido. Con lo cual, su ineficacia quedaría garantizada (argumento teleológico); $i$ ) En consecuencia con el telos de la Convención, el artículo V abre su texto con el adverbio "solo", que significa "únicamente". Y si el significante dice "[únicamente] se podrá denegar el reconocimiento y ejecución [por las causales listadas]", entonces su significado es que no se puede denegar el reconocimiento por ninguna otra causal, y que tampoco se puede reconocer un laudo cuando una causal de denegatoria ha sido probada. Y esto excluye, desde el propio significado convencional del lenguaje empleado, que el mismo sea fuente de poder discrecional alguno para los tribunales del Estado del foro (al menos como no sea haciendo una interpretación contra-literal, donde "solo" no signifique lo que convencionalmente es aceptado que significa: "únicamente). Al contrario, al decir "solo se podrá", se está limitando la competencia judicial en la materia a las causales tasadas por el artículo $\mathrm{V}$ (primer argumento gramatical); iii) Tomado el artículo $\mathrm{V}$ en su integridad, la posibilidad de denegar el reconocimiento, referida en su parágrafo 1, está atada a que, la parte que se opone al mismo, demande y pruebe la causal invocada (textualmente dice "a instancia de la parte contra la cual es invocada" y "si esta parte prueba", respectivamente), lo cual hace sentido cuando contrastado con el parágrafo 2, que, al decir "también se podrá denegar el reconocimiento" y no requerir ni la demanda ni la prueba de parte, está diciendo que las causales por él contempladas pueden operar de oficio. Por tanto, como en el parágrafo 1 la denegación depende del pedido y la prueba que produzca la parte que se opone al reconocimiento, al decir "podrá", la Convención no se está dirigiendo a los tribunales, sino a dicha parte, a la cual le está diciendo que puede defenderse probando que el laudo está incurso en una de las causales tasadas por ella (segundo argumento gramatical). Ya dije, también, que en esta interpretación voy en disenso con la jurisprudencia, que reconoce al artículo V,1 como fuente de poder discrecional.

Y sí estoy de acuerdo con el fundamento, porque el orden público, como tal, es razón suficiente para impedir el paso de una sentencia extranjera de anulación que, de no violarlo, debiera ser admitida y ejecutada en la jurisdicción secundaria con los mismos efectos que produciría en su lugar de origen.

e) En la jurisprudencia comparada el orden público es un concepto de principio. Como tal, es de formulación abstracta, pero de aplicación restrictiva (i.e. no todo hecho repudiable es una violación de principio). En el caso estadounidense, el orden público se contrae a "las nociones más básicas de moralidad y justicia" (Corte de Apelaciones del Segundo Circuito de Estados Unidos, asunto "Parsons \& Whittemore Overseas Co. v. Société Générale 
de l'Industrie du Papier", 1974) ${ }^{24}$. El mismo criterio, incluyendo el lenguaje empleado en su formulación, se usa en Hong Kong (Corte Superior de la Región Administrativa Especial de Hong Kong, asunto "Hebei Import and Export Corporation v. Polytek Engineering Company Ltd", 1998) ${ }^{25} \mathrm{e}$ Irlanda (Corte Superior de Irlanda, asunto "Brostom Tankers AB v. Factorías Vulcano SA", 2004) ${ }^{26}$. Lo mismo que en Alemania y Suiza, donde hay violación al orden público, respectivamente, cuando se infringe "una norma que regula los principios básicos de la vida pública o económica o cuando tal infracción contradice de un modo intolerable el concepto alemán de justicia", o cuando "el sentimiento innato de justicia es lastimado de modo intolerable al inaplicarse una disposición fundamental del sistema jurídico suizo"27. Igual es el caso noruego, en el que hay violación al orden público "únicamente cuando [el laudo] discrepa en grado inaceptable con el orden jurídico del Estado, violando un principio fundamental del mismo" "Pulsarr Industrial Research BV v. Nils H. Pilsen AS”, 2002)28. O en Canadá, donde una violación al orden público es tal por ser "contraria a la moralidad esencial del Estado" (Corte de Ontario, Canadá, asunto "Arcata Graphics Buffalo Ltd. v. Movie-Magazine Corp.”, 1993) ${ }^{29}$. Y en España, país en el que se denomina orden público constitucional al régimen compuesto por los derechos y libertades fundamentales reconocidos en su Constitución ${ }^{30}$. Reconstruido, el orden público es el fundamento ético del sistema jurídico del Estado del foro: es el sustento moral de la filosofía política que lo determina. De ahí que opere como una excepción: excluyendo la aplicación de la ley extranjera que, de otra manera, sería aplicable según las reglas de conflicto; o negando la admisión de los efectos jurídicos de las decisiones y documentos que, si no fuera por dicho motivo, debieran reconocerse.

Por tanto, para denegar el reconocimiento a una decisión de anulación,

24508 F.2d 969.

Fuente: https://bulk.resource.org/courts.gov/c/F2/508/508.F2d.969.741676.74-1642.174.637.html

${ }^{25}$ Fuente:

http://arbitrationlaw.com/files/free_pdfs/hebei_import_and_export_corp_v_ polytek_engineering_co_ltd_cacv_116-1997.pdf

${ }^{26}$ Fuente: http://www.bailii.org/ie/cases/IEHC/2004/198.html

${ }^{27}$ En Ungar, Kenneth, The Enforcement of Arbitral Awards Under UNCITRAL'S Model Law on International Commercial Arbitration, en Columbia Journal of Transnational Law, 25 (1987), p. 751.

${ }^{28}$ En Born, Gary, International Commercial Arbitration: Commentary and Materials (2a edición, La Haya, Kluwer, 2001), p. 740.

${ }^{29}$ Fuente: http://interarb.com/clout/clout037.htm

${ }^{30}$ Cf. Fernández Rozas, José Carlos - Sánchez Lorenzo, Sixto, Derecho internacional privado (2a edición, Madrid, Civitas, 2003), p. 314. 
con fundamento en que de admitirla se violaría el orden público del foro, ningún tribunal necesita apoyarse en los intersticios que le deje el lenguaje de un instrumento convencional. Le basta, simplemente, con fundarse en el propio orden público como tal: en explicitar su contenido y sus alcances normativos y en demostrar la relación antinómica que se produciría si se admitiese la sentencia extranjera. Es el propio orden público la fuente de la denegatoria del reconocimiento. Como tal, es un argumento irrebatible. Frente a él, alegar como fuente el carácter dispositivo del artículo V,1 parece un argumento débil, redundante y distractivo: $i$ ) Débil, porque al eludir el significado convencionalmente aceptado del adverbio "solo", el argumento se vuelve rebatible desde el punto de vista de su corrección racional, por fundarse, implícitamente, en una interpretación contra-literal de dicho adverbio; ii) Redundante, porque la fuente de la denegatoria es el orden público y no el artículo V,1. A contrario: aún si el artículo V,1 dijese "deberá" en vez de "podrá", igual podría denegarse el reconocimiento con fundamento en el orden público; y iii) distractivo, porque dirige la atención a un argumento auxiliar (el poder discrecional para reconocer un laudo que nacería del carácter potestativo del artículo $\mathrm{V}, 1$ ), desviándola del argumento principal (el orden público como tal).

\section{BiBLIOGRAFÍA}

Born, Gary, International Commercial Arbitration: Commentary and Materials (2a edición, La Haya, Kluwer, 2001).

Chapdelaine, Pascale, The Temporal Application of the New York Arbitration Convention of 1958: Retroactivity or Immediate Application? en Arbitration International, 8 (1992).

Davis, Kenneth R., Unconventional Wisdom: A New Look at Articles V and VII of the Convention on the Recognition and Enforcement of Foreign Arbitral Awards, en Texas International Law Journal, 37 (2002).

Fernández Rozas, José Carlos - Sánchez Lorenzo, Sixto, Derecho internacional privado (2a edición, Madrid, Civitas, 2003).

MacCormick, Neil, Legal Reasoning and Legal Theory (1 ${ }^{\text {a }}$ edición, Nueva York, Clarendon Press, 1978).

PARK, William, Duty and Discretion in International Arbitration, en American Journal of International Law, 93 (1999).

Ungar, Kenneth, The Enforcement of Arbitral Awards Under UNCITRAL's Model Law on International Commercial Arbitration, en Columbia Journal of Transnational Law, 25 (1987). 
